\title{
Is the Bond Market Irrational?
}

\author{
Massimo Guidolin
}

$\mathbf{R}$ ecently, financial commentators and central bankers have labeled the failure of long-term rates to rise in the face of an upward trending federal funds rate a "conundrum." Because consumption decisions by households and investment decisions by firms depend on long-term interest rates, the ability to control these rates has been considered an important policymaking tool. The implicit assumption is that bond yields ought to react to changes in yields of short-term instruments. In fact, a common benchmark model holds that simple market forces should make long-term interest rates a weighted average of the short-term interest rates expected to prevail during the period covered by the bond.

I analyze data on 1- and 10-year bond yields and a notion of the short-term rate controlled by the Fed for the period January 1962-May 2005. I find a number of episodes in which long-term rates failed to adjust to changes in short-term rates. Events similar to those in 2004-05 occurred in 1975-78 and 1986-89. Therefore, although unusual, the recent behavior of long-term rates is far from unprecedented.

Scatter plots in the chart show the reaction of both short-term (left panel) and long-term (right panel) bond yields to changes in the Fed target: Each circle corresponds to a change in the Fed target, matched to a measure of the bond market within a period of five trading weeks. Regression lines capture the average reaction.

One would expect to find circles only in quadrants I and III: Changes in the short-term Fed operating target ought to cause changes of the same sign in bond yields.

Moreover, since long-term bond yields should equal weighted averages of current and future short-term rates, such an effect should be stronger on money market instruments than on long-term bonds. The chart shows that short-term interest rates react more to changes in the Fed target than longterm rates do, but, unexpectedly, quadrants II and IV contain many observations. In particular, for more than a third of 204 target changes, the 10-year Treasury note yield moved in the opposite direction of the Fed target.

Should the recent failure of long-term interest rates to react to changes in short-

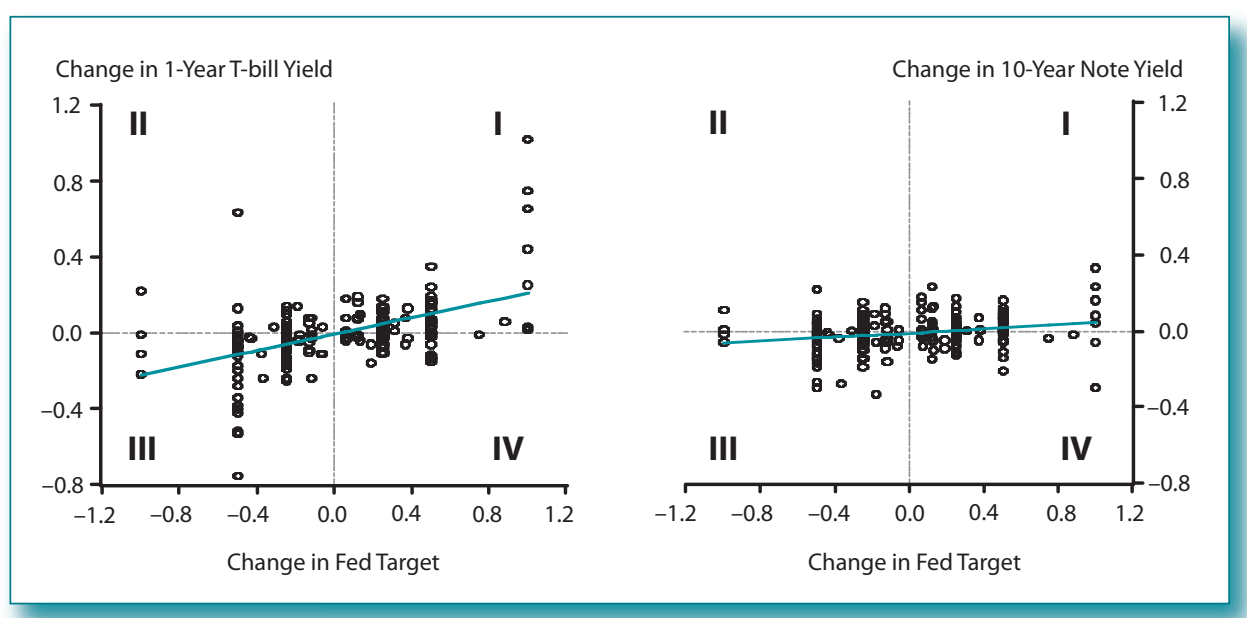

